\title{
High Leptin Level is an Independent Risk Factor of Endometrial Cancer: A Meta- Analysis
}

\author{
Ping-Ping Wang ${ }^{a}$ Xiao-Yan He ${ }^{b}$ Robin Wang ${ }^{c, d}$ Zengfang Wang ${ }^{a}$ \\ Yan-Gang Wang \\ aDepartment of Obstetrics, Maternal and Child Health Hospital of Weifang, Weifang, bepartment \\ of Oncology, People's Hospital of Ganzhou, Ganzhou, 'Department of Endocrinology, the Affiliated \\ Hospital of Medical College, Qingdao University, Qingdao, dDepartment of Internal Medicine, \\ Maternal and Child Health Hospital of Weifang, Weifang, China
}

\author{
Key Words \\ Leptin • Endometrial cancer • Meta-analysis
}

\begin{abstract}
Background/Aims: Previous studies suggested that high leptin level might increase risk of endometrial cancer, but available data were conflicting and whether high leptin level was an independent risk factor of endometrial cancer was still unclear. Therefore, a meta-analysis was performed to assess whether high leptin level was an independent risk factor of endometrial cancer. Methods: PubMed, Web of Science, and Embase databases were searched for epidemiological studies published up to June 26,2014 . The pooled risk ratio (RR) with $95 \%$ confidence interval $(95 \% \mathrm{CI})$ was used to assess the association between leptin level and risk of endometrial cancer. Results: Six studies with a total of 3136 individuals were finally included into the meta-analysis. Meta-analysis of total 6 studies showed that high leptin level was associated with increased risk of endometrial cancer ( $R R=2.55,95 \% C I 1.91-3.41, P<0.001)$. After adjusting for confounding factors, high leptin level was also associated with increased risk of endometrial cancer $(R R=1.59,95 \% C I 1.27-1.98, P<0.001)$. Sensitivity analysis proved the stability of the pooled estimates. The RR of endometrial cancer was 1.10 (95\%CI, 1.03-1.18, $P=0.005)$ per $5 \mathrm{ng} / \mathrm{mL}$ increment in leptin levels. There was no obvious risk of publication bias (P Egger $=0.54)$. Conclusion: Our findings suggest that high leptin level is an independent risk factor of endometrial cancer. More prospective studies are needed to further confirm the association in the future.
\end{abstract}




\section{Introduction}

Endometrial cancer is a major cause of morbidity and mortality for women worldwide, with an estimated 287,100 new cases diagnosed every year [1,2]. It is the sixth most common malignancy in women worldwide. It has been clear that obesity is strongly associated with increased risk of endometrial cancer [2, 3]. Interventions aiming to reducing obesity may provide an effective method for the prevention of endometrial cancer [4-6]. Considering the important role of obesity in the development of cancer, adipokines, such as adiponectin and leptin, are considered to have important roles in the link between obesity and endometrial cancer [7-9]. Leptin is a main kind cytokine produced by adipocytes, which has an important role in the regulation of energy balance and glucose metabolism [10-12]. Previous studies have suggested both hyperinsulinemia and obesity are associated with high leptin levels, and leptin can decrease tissues' sensitivity to insulin and lead to higher insulin levels $[10,12]$. Numerous studies have assessed the role of leptin on risks of various cancers, but there are no studies with confirming conclusion $[11,12]$. There were also several published studies investigating whether high leptin level could increase the risk of endometrial cancer, but they provided conflicting data and whether high leptin level is an independent risk factor of endometrial cancer is still unclear [13-17]. It's no doubt that more convincing evidence is needed to fully elucidate the exact role of leptin in the development of endometrial cancer, since identification of the connection between leptin and endometrial cancer can help us both get a better understanding of endometrial carcinogenesis and develop some preventive strategies against endometrial cancer. Therefore, a meta-analysis was performed in present study to assess whether high leptin level was an independent risk factor of endometrial cancer.

\section{Materials and Methods}

Search strategy

PubMed, Web of Science, and Embase databases were searched for epidemiological studies published up to June 26, 2014. The following search terms were used in combination to retrieve the relevant literatures in all these databases above: (leptin or adipokines) and (endometrial cancer or endometrial carcinoma). Reference lists of articles were scrutinized to identify additional articles. There was no language limitation in the literature search.

\section{Eligibility criteria}

Studies were included in the meta-analysis if they met the following criteria: (1) the study must be an original epidemiologic study of cohort, nested case-control, or case-control studies; (2) the exposure of interest was the (serum or plasma) leptin levels detecting in blood samples; (3) the outcome of interest was endometrial cancer incidence; (4) the article must report odds ratio (OR) or relative risk (RR), corresponding $95 \%$ confidence intervals $(95 \% \mathrm{CI})$ to assess the effect of leptin levels on endometrial cancer risk.

\section{Data extraction}

Two investigators performed the data extraction independently. If there was any disagreement between the two investigators, it was resolved by consensus with a third investigator. The following data were extracted from each included study: first author's name, publication year, country, study design, number of subjects, OR or RR with 95\%CI, and confounders adjusted for in multivariate analysis.

\section{Statistical analysis}

The pooled RR with 95\%CI was used to assess the association between leptin level and risk of endometrial cancer. Heterogeneity of effect size among studies was assessed by the Cochran's Q-test and estimated the amount of variation due to heterogeneity by calculating the $\mathrm{I}^{2}$ value $[18,19]$. If $\mathrm{I}^{2}$ was more than $50 \%$ and substantial heterogeneity existed, the random-effects model was used to pool the results 
Table 1. Characteristics of those six studies assessing the association between leptin level and risk of endometrial cancer. (BMI, Body mass index; ELISA, Enzyme-linked immunosorbent assay; RIA, Radioimmunoassay)

\begin{tabular}{|c|c|c|c|c|c|}
\hline Author, year (ref.) & Country & $\begin{array}{l}\text { Participants } \\
\text { (Case/Control) }\end{array}$ & $\begin{array}{l}\text { Study } \\
\text { design }\end{array}$ & $\begin{array}{l}\text { Leptin } \\
\text { assay }\end{array}$ & Adjusted confounding factors \\
\hline Ma et al., 2013 [29] & China & $206 / 310$ & $\begin{array}{l}\text { Case- } \\
\text { control }\end{array}$ & ELISA & $\begin{array}{l}\text { BMI, glucose, cholesterol, triglycerides, } \\
\text { highdensity lipoprotein cholesterol, age, } \\
\text { insulin and leptin-to-adiponectin. }\end{array}$ \\
\hline $\begin{array}{l}\text { Luhn et al., } 2013 \\
\text { [17] }\end{array}$ & USA & $167 / 327$ & $\begin{array}{l}\text { Nested } \\
\text { case- } \\
\text { control }\end{array}$ & RIA & $\begin{array}{l}\text { Family history of breast or endometrial } \\
\text { cancer, education level, parity, history of } \\
\text { diabetes diagnosis, oral contraceptive use, } \\
\text { and current smoking status, BMI, and } \\
\text { estradiol }\end{array}$ \\
\hline $\begin{array}{l}\text { Dallal et al., } 2013 \\
\text { [16] }\end{array}$ & USA & $62 / 124$ & $\begin{array}{l}\text { Nested } \\
\text { case- } \\
\text { control }\end{array}$ & ELISA & $\begin{array}{l}\text { Age at baseline/blood drawG5 years, clinic } \\
\text { site, time of blood drawG2 h, trial } \\
\text { participation status, Estradiol, C-peptide, and } \\
\text { BMI. }\end{array}$ \\
\hline $\begin{array}{l}\text { Friedenreich et al., } \\
2012 \text { [15] }\end{array}$ & Canada & $514 /$ & $\begin{array}{l}\text { Case- } \\
\text { control }\end{array}$ & ELISA & $\begin{array}{l}\text { Age at reference, nulliparous, menopausal } \\
\text { hormone use, hypertension, weight at } \\
\text { reference date, and waist-to-hip ratio. }\end{array}$ \\
\hline $\begin{array}{l}\text { Ashizawa et al., } \\
2010[14]\end{array}$ & Japan & $146 / 150$ & $\begin{array}{l}\text { Nested } \\
\text { case- } \\
\text { control }\end{array}$ & RIA & Age, BMI, hypertension, and diabetes mellitus. \\
\hline $\begin{array}{l}\text { Petridou et al., } 2002 \\
\text { [13] }\end{array}$ & Greece & $84 / 84$ & $\begin{array}{l}\text { Case- } \\
\text { control }\end{array}$ & RIA & $\begin{array}{l}\text { Age, education, height, age at menarche, } \\
\text { menopausal status, history of pregnancies by } \\
\text { outcome, alcohol and coffee consumption, and } \\
\text { smoking status, total energy intake, and BMI. }\end{array}$ \\
\hline
\end{tabular}

according to the DerSimonian-Laird method [20]; Otherwise, the fixed-effects model was adopted as the pooling method [18]. Sensitivity analysis by removal of individual studies by turns was performed to assess the robustness of the pooled results of meta-analysis. To assess the possible dose-response relationship between leptin levels and incidence of endometrial cancer, a multivariate random-effects meta-analysis taking into account the between-study heterogeneity was performed to compute the trend from the correlated RR estimates across categories of leptin levels [21]. Publication bias was tested by means of funnel plot and Egger's test $[22,23]$. All statistical analyses were performed with STATA version 12.0 (Stata Corporation, College Station, TX, USA). All reported P values were two-sided, and $\mathrm{P}<0.05$ was considered statistically significant.

\section{Results}

\section{Study selection and characteristics}

We identified 105 potentially relevant articles concerning the association between leptin level and endometrial cancer risk. After checking the abstracts, 94 articles were firstly excluded because they were obvious irrelevant studies, reviews, or case reports. The left 11 articles were further evaluated by full-text, and five studies were excluded including 4 studies without usable data [24-27] and one study without relevant exposure [28]. Finally, 6 articles with a total of 3136 individuals were finally included into the meta-analysis [13-17]. Those 6 studies included 3 nested case-control studies and 3 case-control studies. All studies provided adjusted estimates for the association between leptin level and risk of endometrial cancer. Table 1 shows the main characteristics of those six studies included into the metaanalysis (Table 1).

\section{Meta-analysis}

Meta-analysis of total 6 studies showed that high leptin level was associated with increased risk of endometrial cancer ( $R R=2.55,95 \%$ CI 1.91-3.41, $\mathrm{P}<0.001$ ) (Fig. 1A). After adjusting for confounding factors, high leptin level was also associated with increased risk of endometrial cancer ( $R R=1.59,95 \%$ CI 1.27-1.98, $\mathrm{P}<0.001$ ) (Fig. 1B). After adjusting for BMI and other factors, high leptin level was still associated with increased risk of endometrial cancer (RR $=1.67,95 \%$ CI 1.28-2.17, P < 0.001) (Fig. 1C). Subgroup analysis by study design found similar findings $(\mathrm{P}<0.01)$. Sensitivity analysis by removal of individual studies by turns showed no obvious influence of individual study on the pooled estimate, which proved 
Fig. 1. The effect of leptin levels on endometrial cancer risk. (A) Unadjusted effect. (B) Adjusted for possible confounding factors. (C) Adjusted for BMI and all other possible confounding factors.

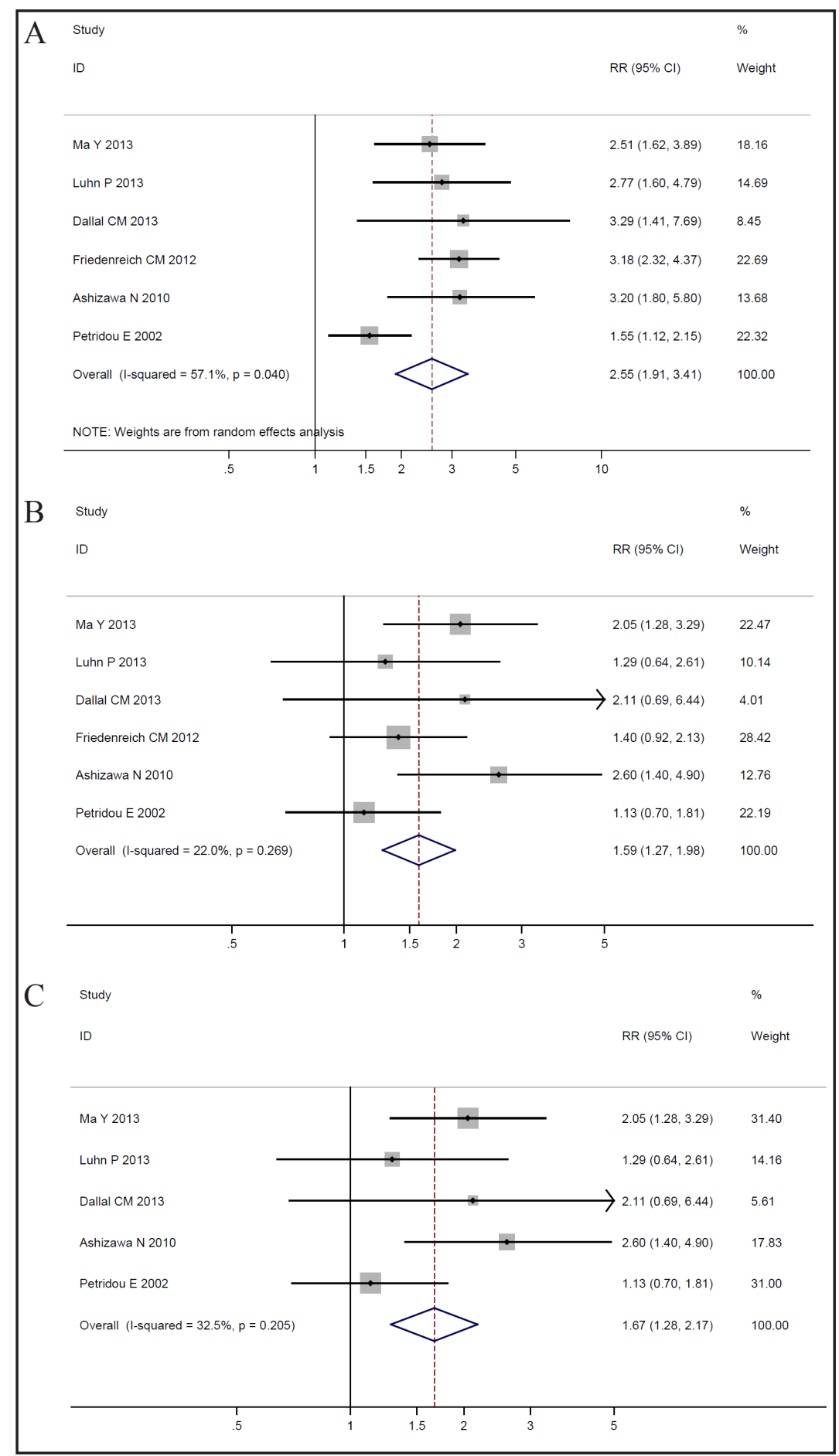

the stability of the pooled estimates. The dose-response meta-analysis showed that RR of endometrial cancer was $1.10(95 \% \mathrm{CI}, 1.03-1.18, \mathrm{P}=0.005)$ per $5 \mathrm{ng} / \mathrm{mL}$ increment in leptin level (Fig. 2).

\section{Publication bias}

The funnel plot showed no obvious evidence of publication bias (Fig. 3). In addition, Egger's regression test also showed that there was no obvious risk of publication bias $\left(\mathrm{P}_{\text {Egger }}\right.$ $=0.54$ ). 
Fig. 2. The dose-response analysis between leptin level and risk of endometrial cancer with restricted cubic splines in a multivariate random-effects dose-response model. (The solid line and the long dash line represent the estimated relative risk and its $95 \%$ confidence interval of the nonlinear relationship. Short dash line represents the linear relationship.)

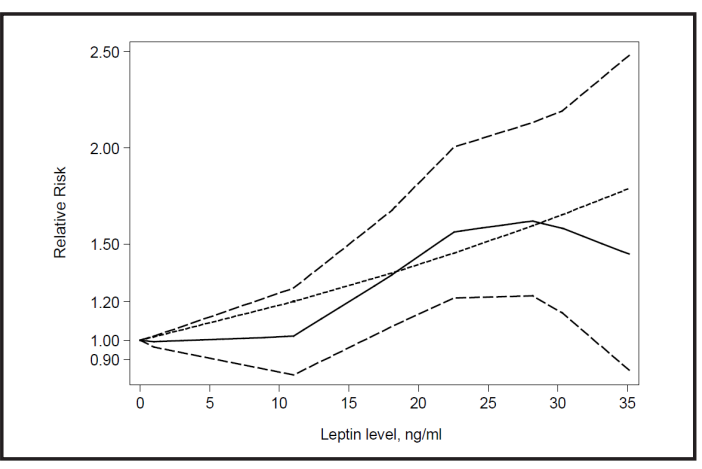

Fig. 3. Begg's funnel plot showed no obvious evidence of publication bias.

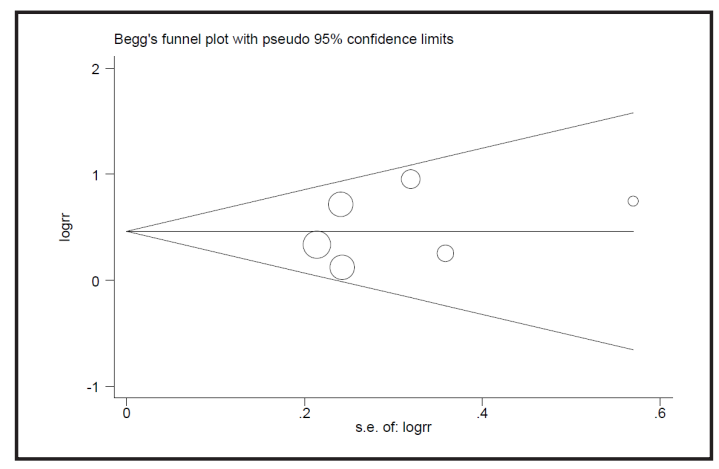

\section{Discussion}

Though several studies were performed to assess the role of leptin levels on risk of endometrial cancer, they provided conflicting results. In addition, whether high leptin level is an independent risk factor of endometrial cancer is still unclear. Therefore, we performed this meta-analysis assess whether high leptin level was an independent risk factor of endometrial cancer. To the best of our knowledge, it is the first meta-analysis aiming to comprehensively assess the association between leptin levels and endometrial cancer risk. Our meta-analysis provides an appropriate approach to obtain a more definitive conclusion regarding the role of leptin in the development of endometrial cancer and allows a much bigger possibility of reaching reasonable conclusion.

Six studies with a total of 3136 individuals were finally included into the meta-analysis [13-17, 29]. Meta-analysis of total 6 studies showed that high leptin level was associated with increased risk of endometrial cancer (Fig. 1). After adjusting for BMI and other factors, high leptin level was still associated with increased risk of endometrial cancer $(\mathrm{RR}=1.67$, 95\%CI 1.28-2.17, P < 0.001) (Fig. 1). Therefore, our findings suggest that high leptin level is an independent risk factor of endometrial cancer, and leptin indeed plays important roles in the carcinogenesis of endometrial cancer.

Though obesity has been identified as an important risk factor of endometrial cancer, the exact mechanism is still unclear. Adipokines, including leptin, are believed to play important roles in the link between obesity and endometrial cancer [30-32]. Our findings suggest that high leptin level is an independent risk factor of endometrial cancer, which further suggests a major role for leptin in endometrial carcinogenesis independent of obesity. In addition, the $\mathrm{RR}$ of developing endometrial cancer is 1.10 (95\%CI, 1.03-1.18) per $5 \mathrm{ng} / \mathrm{mL}$ increment in the leptin level (Fig. 2), and there is an obvious dose-response relationship between leptin levels and risk of endometrial cancer, and individuals with high levels of leptin have higher risk of developing endometrial cancer.

Obesity is associated with increased endometrial cancer risk, and leptin is an important biomarker of obesity. But the findings from the meta-analysis shows that high leptin level 
is an independent risk factor of endometrial cancer independent of BMI, which indicates that leptin may be involved in the endometrial carcinogenesis by other pathways. Previous studies have suggested that leptin plays a major role in the regulation of glucose, insulinsensitizing activity, inflammation, lipid homeostasis, and other pathophysiology involved in carcinogenesis [33-35]. Previous studies also have suggested that leptin can stimulate cell growth, invasion, and angiogenesis via activating different signaling pathways $[9,36$, 37], which may promote the development of endometrial cancer. However, the potential mechanisms underlying the association between leptin and endometrial cancer are complex, and it needs more future studies.

Some limitations should be considered when interpreting the results in the metaanalysis. Firstly, although three databases (PubMed, Web of Science, and Embase) were searched for possible studies, there was no obvious risk of publication bias, it was possible that some unpublished studies with negative findings were not indexed in those three databases and was impossible to be included into the meta-analysis. In addition, studies published in non-English language were also indexed in common databases, which could result in the risk of language bias in the meta-analysis. Secondly, the present meta-analysis included 6 studies, and three of them were case-control design. Since the case-control studies are easily subject to selection bias, the inherent limitations of such studies may influence the findings from the meta-analysis. To reduce the risk of bias, more studies with reasonable design and prospective design are needed to further assess the role of leptin in endometrial carcinogenesis. Finally, considering the small number of studies included in our metaanalysis, it is worth noting that the validity of pooled estimates needs further identification. Further studies with large number of participants are needed to identify the findings from the meta-analysis.

Despite these three limitations, our meta-analysis has several strengths. First, six studies with a total of 3136 individuals were included into the meta-analysis. The large sample size of pooled size allowed us to get a more precise assessment on the relation between leptin level and endometrial cancer, and obtain a more definitive conclusion regarding the role of leptin in the development of endometrial cancer. Second, the control of confounding factors, especially BMI, allowed us to decrease the risk of bias and get an exact assessment of the relation between leptin level and endometrial cancer. Finally, the multivariate random-effects meta-analysis in present study suggests that there is an obvious dose-response relationship between leptin levels and incidence of endometrial cancer, with a 1.10 (95\%CI, 1.03-1.18) incensement of RR for endometrial cancer per $5 \mathrm{ng} / \mathrm{mL}$ increment in leptin level (Fig. 2). The dose-response relationship adds the strength for the obvious association between leptin levels and risk of endometrial cancer.

In conclusion, our findings suggest that high leptin level is an independent risk factor of endometrial cancer, and there an obvious dose-response relationship between leptin levels and incidence of endometrial cancer. In addition, more prospective studies are needed to further confirm the association in the future.

\section{Disclosure Statement}

We declare that we have no conflicts of interest.

\section{References}

1 Jemal A, Bray F, Center MM, Ferlay J, Ward E, Forman D: Global cancer statistics. CA Cancer J Clin 2011;61:69-90.

2 Wright JD, Barrena Medel NI, Sehouli J, Fujiwara K, Herzog TJ: Contemporary management of endometrial cancer. Lancet 2012;379:1352-1360. 


\begin{tabular}{|c|c|c|}
\hline Cellular & Cell Physiol Biochem 2014;34:1477-1484 & \\
\hline and Biochemistry & $\begin{array}{l}\text { Dol: } 10.1159 / 000366352 \\
\text { Published online: October } 08,2014\end{array}$ & $\begin{array}{l}\text { O } 2014 \text { S. Karger AG, Basel } \\
\text { www.karger.com/cpb }\end{array}$ \\
\hline
\end{tabular}

3 Zhang Y, Liu H, Yang S, Zhang J, Qian L, Chen X: Overweight, obesity and endometrial cancer risk: Results from a systematic review and meta-analysis. Int J Biol Markers 2014;29:e21-29.

4 Boeing H: Obesity and cancer--the update 2013. Best Pract Res Clin Endocrinol Metab 2013;27:219-227.

5 Schmandt RE, Iglesias DA, Co NN, Lu KH: Understanding obesity and endometrial cancer risk: Opportunities for prevention. Am J Obstet Gynecol 2011;205:518-525.

6 De Pergola G, Silvestris F: Obesity as a major risk factor for cancer. J Obes 2013;2013:291546.

7 Fader AN, Arriba LN, Frasure HE, von Gruenigen VE: Endometrial cancer and obesity: Epidemiology, biomarkers, prevention and survivorship. Gynecol Oncol 2009;114:121-127.

$>8$ Bray GA: The underlying basis for obesity: Relationship to cancer. J Nutr 2002;132:3451S-3455S.

Sharma D, Saxena NK, Vertino PM, Anania FA: Leptin promotes the proliferative response and invasiveness in human endometrial cancer cells by activating multiple signal-transduction pathways. Endocr Relat Cancer 2006;13:629-640.

10 Elias CF: Leptin action in pubertal development: Recent advances and unanswered questions. Trends Endocrinol Metab 2012;23:9-15.

$\checkmark 11$ Ando S, Catalano S: The multifactorial role of leptin in driving the breast cancer microenvironment. Nat Rev Endocrinol 2012;8:263-275.

12 Mantzoros CS, Magkos F, Brinkoetter M, Sienkiewicz E, Dardeno TA, Kim SY, Hamnvik OP, Koniaris A: Leptin in human physiology and pathophysiology. Am J Physiol Endocrinol Metab 2011;301:E567-584.

13 Petridou E, Belechri M, Dessypris N, Koukoulomatis P, Diakomanolis E, Spanos E, Trichopoulos D: Leptin and body mass index in relation to endometrial cancer risk. Ann Nutr Metab 2002;46:147-151.

14 Ashizawa N, Yahata T, Quan J, Adachi S, Yoshihara K, Tanaka K: Serum leptin-adiponectin ratio and endometrial cancer risk in postmenopausal female subjects. Gynecol Oncol 2010;119:65-69.

-15 Friedenreich CM, Langley AR, Speidel TP, Lau DC, Courneya KS, Csizmadi I, Magliocco AM, Yasui Y, Cook LS: Case-control study of markers of insulin resistance and endometrial cancer risk. Endocr Relat Cancer 2012;19:785-792.

16 Dallal CM, Brinton LA, Bauer DC, Buist DS, Cauley JA, Hue TF, Lacroix A, Tice JA, Chia VM, Falk R, Pfeiffer R, Pollak M, Veenstra TD, Xu X, Lacey JV Jr: Obesity-related hormones and endometrial cancer among postmenopausal women: A nested case-control study within the $\mathrm{b} \sim$ fit cohort. Endocr Relat Cancer 2013;20:151-160.

17 Luhn P, Dallal CM, Weiss JM, Black A, Huang WY, Lacey JV Jr, Hayes RB, Stanczyk FZ, Wentzensen N, Brinton LA: Circulating adipokine levels and endometrial cancer risk in the prostate, lung, colorectal, and ovarian cancer screening trial. Cancer Epidemiol Biomarkers Prev 2013;22:1304-1312.

18 Cochran WG: The combination of estimates from different experiments. Biometrics 1954;10:101-129.

19 Higgins JP, Thompson SG, Deeks JJ, Altman DG: Measuring inconsistency in meta-analyses. BMJ 2003;327:557-560.

20 DerSimonian R, Laird N: Meta-analysis in clinical trials. Control Clin Trials 1986;7:177-188.

21 Orsini N, Li R, Wolk A, Khudyakov P, Spiegelman D: Meta-analysis for linear and nonlinear dose-response relations: Examples, an evaluation of approximations, and software. Am J Epidemiol 2012;175:66-73.

-22 Egger M, Davey Smith G, Schneider M, Minder C: Bias in meta-analysis detected by a simple, graphical test. BMJ 1997;315:629-634.

23 Begg CB, Mazumdar M: Operating characteristics of a rank correlation test for publication bias. Biometrics 1994;50:1088-1101.

24 Yuan SS, Tsai KB, Chung YF, Chan TF, Yeh YT, Tsai LY, Su JH: Aberrant expression and possible involvement of the leptin receptor in endometrial cancer. Gynecol Oncol 2004;92:769-775.

25 Karahanoglu E, Adanir I, Boyraz G, Sahin N, Tuncer ZS: Preoperative serum leptin levels in patients with endometrial cancer and its correlation with prognostic variables. Eur J Gynaecol Oncol 2012;33:278-280.

26 Modesitt SC, Geffel DL, Via J, A LW: Morbidly obese women with and without endometrial cancer: Are there differences in measured physical fitness, body composition, or hormones? Gynecol Oncol 2012;124:431436.

27 Mihu D, Ciortea R, Mihu CM: Abdominal adiposity through adipocyte secretion products, a risk factor for endometrial cancer. Gynecol Endocrinol 2013;29:448-451. 
-28 Cust AE, Kaaks R, Friedenreich C, Bonnet F, Laville M, Lukanova A, Rinaldi S, Dossus L, Slimani N, Lundin E, Tjonneland A, Olsen A, Overvad K, Clavel-Chapelon F, Mesrine S, Joulin V, Linseisen J, Rohrmann S, Pischon T, Boeing H, Trichopoulos D, Trichopoulou A, Benetou V, Palli D, Berrino F, Tumino R, Sacerdote C, Mattiello A, Quiros JR, Mendez MA, Sanchez MJ, Larranaga N, Tormo MJ, Ardanaz E, Bueno-de-Mesquita HB, Peeters PH, van Gils CH, Khaw KT, Bingham S, Allen N, Key T, Jenab M, Riboli E: Plasma adiponectin levels and endometrial cancer risk in pre- and postmenopausal women. J Clin Endocrinol Metab 2007;92:255-263.

29 Ma Y, Liu Z, Zhang Y, Lu B: Serum leptin, adiponectin and endometrial cancer risk in chinese women. J Gynecol Oncol 2013;24:336-341.

-30 Gao J, Tian J, Lv Y, Shi F, Kong F, Shi H, Zhao L: Leptin induces functional activation of cyclooxygenase-2 through jak2/stat3, mapk/erk, and pi3k/akt pathways in human endometrial cancer cells. Cancer Sci 2009;100:389-395.

-31 Catalano S, Giordano C, Rizza P, Gu G, Barone I, Bonofiglio D, Giordano F, Malivindi R, Gaccione D, Lanzino M, De Amicis F, Ando S: Evidence that leptin through stat and creb signaling enhances cyclin d1 expression and promotes human endometrial cancer proliferation. J Cell Physiol 2009;218:490-500.

32 Carino C, Olawaiye AB, Cherfils S, Serikawa T, Lynch MP, Rueda BR, Gonzalez RR: Leptin regulation of proangiogenic molecules in benign and cancerous endometrial cells. Int J Cancer 2008;123:2782-2790.

-33 Chen C, Chang YC, Lan MS, Breslin M: Leptin stimulates ovarian cancer cell growth and inhibits apoptosis by increasing cyclin $\mathrm{d} 1$ and mcl-1 expression via the activation of the mek/erk $1 / 2$ and pi3k/akt signaling pathways. Int J Oncol 2013;42:1113-1119.

-34 Mu N, Zhu Y, Wang Y, Zhang H, Xue F: Insulin resistance: A significant risk factor of endometrial cancer. Gynecol Oncol 2012;125:751-757.

- 35 Koda M, Sulkowska M, Wincewicz A, Kanczuga-Koda L, Musiatowicz B, Szymanska M, Sulkowski S: Expression of leptin, leptin receptor, and hypoxia-inducible factor 1 alpha in human endometrial cancer. Ann N Y Acad Sci 2007;1095:90-98.

-36 Liu L, Wang L, Zheng J, Tang GL Leptin promotes human endometrial carcinoma cell proliferation by enhancing aromatase (P450arom) expression and estradiol formation. Eur J Obstet Gynecol Reprod Biol 2013;170:198-201.

- 37 Bitton-Worms K, Rostoker R, Braun S, Shen-Orr Z, LeRoith D: The effect of leptin administration on mammary tumor growth in diabetic mice. Horm Metab Res 2013;45:655-659. 